\title{
CARACTERIZAÇÃO MORFOMÉTRICA DA BACIA HIDROGRÁFICA DO RIO DEBOSSAN, NOVA FRIBURGO, RJ ${ }^{1}$
}

\author{
Christiany Araujo Cardoso ${ }^{2}$, Herly Carlos Teixeira Dias ${ }^{3}$, Carlos Pedro Boechat Soares ${ }^{3}$ e Sebastião \\ Venâncio Martins ${ }^{3}$
}

\begin{abstract}
RESUMO - O objetivo deste trabalho foi fazer a caracterização morfométrica a partir de alguns parâmetros físicos da bacia hidrográfica do rio Debossan, Nova Friburgo, RJ. Para isso, gerou-se inicialmente o Modelo Digital de Elevação Hidrologicamente Consistente (MDEHC) a partir de cartas topográficas do IBGE, na escala 1:50.000, utilizando o sistema de informações geográficas, através dos softwares ArcVIEW e Arc/INFO. A partir do MDEHC, foram calculados alguns parâmetros morfométricos para o estudo do comportamento hidrológico da bacia. A área de drenagem encontrada foi de $9,9156 \mathrm{~km}^{2}$ e o perímetro, de $17,684 \mathrm{~km}$. A bacia hidrográfica do rio Debossan tem formato alongado, coeficiente de compacidade de 1,5842, fator de forma de 0,3285 e índice de circularidade de 0,3985 . A densidade de drenagem obtida para a bacia foi de $2,3579 \mathrm{~km} / \mathrm{km}^{2}$. A forma mais alongada da bacia hidrográfica indica que a precipitação pluviométrica sobre ela se concentra em diferentes pontos, concorrendo para amenizar a influência da intensidade de chuvas, as quais poderiam causar maiores variações da vazão do curso d'água.
\end{abstract}

Palavras-chave: Bacia hidrográfica, morfometria e hidrologia florestal.

\section{MORPHOMETRIC CHARACTERIZATION OF DEBOSSAN RIVER WATERSHED, NOVA FRIBURGO, RJ}

\begin{abstract}
The objective of this work was to perform a morphometric characterization based on some physical parameters. In order to do so, a Hydrologically Consistent Digital Elevation Model (HCDEM) was generated from IBGE topographical maps, scale 1:50.000, using as database and analysis the system of geographic information, by means of the ArcVIEW and Arc/INFO version 8.3 systems. From this, some morphometric parameters of a previous study on the hydrologic behavior of the watershed were calculated. The drainage area was 9,9156 $\mathrm{Km}^{2}$ and 17,684 $\mathrm{km}$ in perimeter. The Debossan river watershed was proven not easily subject to floods as the compacity coefficient was far from the unit (1.5842) and its shape factor presented a low value (0.3285). Such fact can still be proven by the circularity index value (0.3985). The drainage density was 2,3579 $\mathrm{Km} / \mathrm{Km}^{2}$, showing that the watershed has average draining capacity. The drainage system forms a dendritic pattern. This pattern occurs in high lands, in which the regolith and the parent rock relatively provide a uniform resistance to erosion. The more elongated watershed shape, as the circularity index, shape factor and compacity coefficient, indicates that the rainwater volume that falls within the watershed is concentrated in different points, contributing to reduce rain intensities that could cause greater flow variations.
\end{abstract}

Keywords: Watershed, morphometry and forest hydrology.

\footnotetext{
${ }^{1}$ Recebido em 18.03.2005 e aceito para publicação em 10.11.2005.

${ }^{2}$ Programa de Pós-Graduação em Ciência Florestal da Universidade Federal de Viçosa.

${ }^{3}$ Departamento de Engenharia Florestal da UFV. E-mail: <herly@ufv.br>.
} 


\section{INTRODUÇÃO}

A bacia hidrográfica é definida como uma área de captação natural da água da precipitação que faz convergir os escoamentos para um único ponto de saída, seu exutório. É composta basicamente de um conjunto de superfícies vertentes e de uma rede de drenagem formada por cursos d'água que confluem até resultar um leito único no exutório (SILVEIRA, 2001).

Os principais componentes - solo, água, vegetação e fauna - coexistem em permanente e dinâmica interação, respondendo às interferências naturais e àquelas de natureza antrópica, afetando os ecossistemas como um todo. Nesses compartimentos naturais - bacias hidrográficas -, os recursos hídricos constituem indicadores das condições dos ecossistemas, no que se refere aos efeitos do desequilíbrio das interações dos respectivos componentes (SOUZA et al., 2002).

Pelo caráter integrador, Guerra e Cunha (1996) citaram que as bacias hidrográficas são consideradas excelentes unidades de gestão dos elementos naturais e sociais, pois, nessa óptica, é possível acompanhar as mudanças introduzidas pelo homem e as respectivas respostas da natureza. Ainda de acordo com esses autores, em nações mais desenvolvidas a bacia hidrográfica também tem sido utilizada como unidade de planejamento e gerenciamento, compatibilizando os diversos usos e interesses pela água e garantindo sua qualidade e quantidade.

A delimitação de uma bacia hidrográfica é um dos primeiros e mais comuns procedimentos executados em análises hidrológicas ou ambientais. Para isso, tem sido comum a utilização de informações de relevo em formato analógico, como mapas e cartas, o que compromete a confiabilidade e a reprodução dos resultados devidos à carga de subjetividade inerente aos métodos manuais. Com o advento e consolidação dos Sistemas de Informações Geográficas e, conseqüentemente, o surgimento de formas digitais consistentes de representação do relevo, como os Modelos Digitais de Elevação (MDEs), métodos automáticos para delimitação de bacias têm sido desenvolvidos desde então (GARBRECHT e MARTZ, 1999).

Segundo Ferreira (1997), os Sistemas de Informações Geográficas podem ser considerados um instrumento para mapear e indicar respostas às várias questões

R. Árvore, Viçosa-MG, v.30, n.2, p.241-248, 2006 sobre planejamentos urbano e regional, meio rural e levantamento dos recursos renováveis, descrevendo os mecanismos das mudanças que operam no meio ambiente e auxiliando o planejamento e manejo dos recursos naturais de regiões específicas.

Diante do exposto, o objetivo deste trabalho foi fazer uma caracterização morfométrica da bacia hidrográfica do rio Debossan, a partir da estimativa de alguns parâmetros físicos, como: coeficiente de compacidade, fator de forma, índice de circularidade, declividade, altitude, ordem e densidade de drenagem.

\section{MATERIAL E MÉTODOS}

\section{1. Área de Estudo}

A área de estudo compreendeu a bacia de contribuição a montante da estação de captação de água, administrada a aproximadamente 6 anos pela Concessionária de Águas e Esgotos de Nova Friburgo (CAENF). Encontra-se situada no Município de Nova Friburgo, RJ, a 137 km da capital do Estado do Rio de Janeiro (Figura 1).

A bacia é formadora do rio Debossan, sendo um importante afluente do rio Bengalas. Este, por sua vez, tributário do rio Paraíba do Sul. Está inserida na Reserva Ecológica de Macaé de Cima, a qual é totalmente coberta por fragmento de Mata Atlântica.

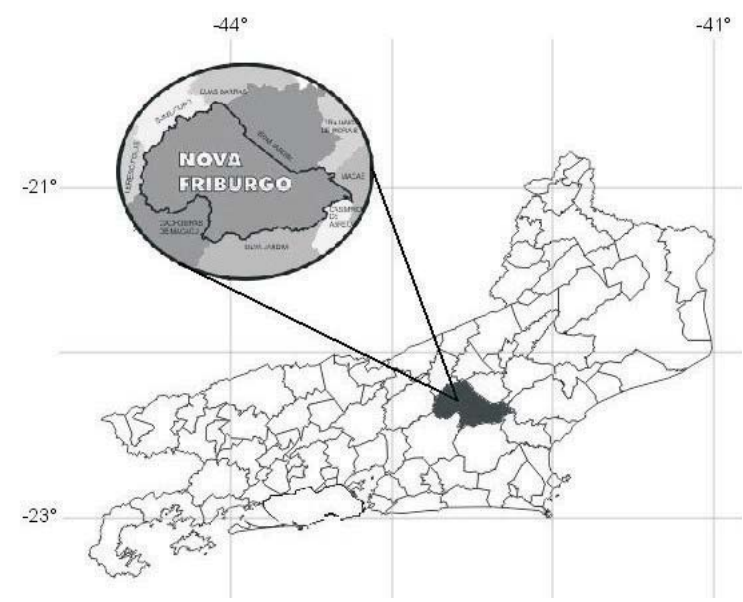

Figura 1 - Localização de Nova Friburgo em relação ao Estado do Rio de Janeiro.

Figure 1 - Nova Friburgo localization within the state of Rio de Janeiro.

\section{R. Árvore, Viçosa-MG, v.30, n.2, p.241-248, 2006}


A vegetação da reserva apresenta uma fisionomia predominantemente florestal, cuja classificação fitogeográfica é Floresta Ombrófila Densa Montana (VELLOSO et al., 1991) ou Floresta Pluvial Atlântica Montana (RIZZINI, 1979).

A classe de solo predominante na região é o Cambissolo, com ocorrência de latossolos (RADAMBRASIL, 1983). O clima regional é do tipo superúmido e mesotérmico na classificação de Thornthwaite (1955), correspondendo à designação Cfb, de Köppen (BERNARDES, 1952).

\subsection{Caracterização Morfométrica da Bacia Hidrográfica}

\subsubsection{Modelo Digital de Elevação Hidrologicamente Consistente (MDEHC)}

A metodologia utilizada para a geração do MDEHC foi executada em quatro etapas.

Primeiramente, obtiveram-se os mapas a partir da base de dados do IBGE na escala 1:50.000 com curvas de nível de 20 em $20 \mathrm{~m}$, em que se utilizaram as cartas topográficas de Nova Friburgo - SF23-Z-B-II-4 e Quartéis -SF23-Z-B-III-3.

Após a obtenção dos mapas, procedeu-se ao préprocessamento dos dados digitais de elevação e drenagem.

A grande maioria dos softwares que geram o Modelo Digital de Elevação necessita de que os dados digitais de entrada estejam com qualidade e estrutura aceitáveis. Para isso, devem-se gerar arquivos individuais contendo os limites da área de trabalho, a hidrografia digital conectada e orientada no sentido do escoamento superficial e dados de altimetria discriminados em curvas de nível e pontos cotados. Posteriormente, foi gerado o Modelo Digital de Elevação (MDE), finalizando com o pós-processamento para geração do MDEHC.

Essa última etapa visou eliminar as depressões espúrias, ou seja, células cercadas por outras com maiores valores de elevação, remanescentes ou que foram introduzidas no MDE durante o processo de imposição da rede de drenagem.

A base de dados e as análises foram geradas através do sistema de informações geográficas, utilizando-se os softwares $A r c V I E W$ e $A r c / I N F O$ versão 8.3.

\subsubsection{Morfometria da Bacia Hidrográfica}

De posse da delimitação da área da bacia, obtiveramse diferentes características físicas, como: área da bacia, perímetro, coeficiente de compacidade, fator de forma, índice de circularidade, declividade, altitude, densidade de drenagem e ordem dos cursos d'água.

\subsubsection{Coeficiente de Compacidade}

O coeficiente de compacidade $(\mathrm{Kc})$ relaciona a forma da bacia com um círculo. Constitui a relação entre o perímetro da bacia e a circunferência de um círculo de área igual à da bacia. De acordo com Villela e Mattos (1975), esse coeficiente é um número adimensional que varia com a forma da bacia, independentemente de seu tamanho. Quanto mais irregular for a bacia, maior será o coeficiente de compacidade. Um coeficiente mínimo igual à unidade corresponderia a uma bacia circular e, para uma bacia alongada, seu valor é significativamente superior a 1. Uma bacia será mais suscetível a enchentes mais acentuadas quando seu Kc for mais próximo da unidade. $\mathrm{O} \mathrm{Kc}$ foi determinado baseado na seguinte equação:

$$
K c=0,28 \frac{P}{\sqrt{A}}
$$

sendo: Kc o coeficiente de compacidade, $\mathrm{P}$ o perímetro (m) e A a área de drenagem $\left(\mathrm{m}^{2}\right)$.

\subsubsection{Fator de Forma}

Relaciona a forma da bacia com a de um retângulo, correspondendo à razão entre a largura média e o comprimento axial da bacia (da foz ao ponto mais longínquo do espigão).

A forma da bacia, bem como a forma do sistema de drenagem, pode ser influenciada por algumas características, principalmente pela geologia. Podem atuar também sobre alguns processos hidrológicos ou sobre o comportamento hidrológico da bacia. Segundo Villela e Mattos (1975), uma bacia com um fator de forma baixo é menos sujeita a enchentes que outra de mesmo tamanho, porém com fator de forma maior. $\mathrm{O}$ fator de forma (F) foi determinado, utilizando-se a seguinte equação:

$$
F=\frac{A}{L^{2}}
$$

sendo o F: fator de forma, A a área de drenagem $\left(\mathrm{m}^{2}\right)$ e L o comprimento do eixo da bacia $(\mathrm{m})$.

R. Árvore, Viçosa-MG, v.30, n.2, p.241-248, 2006 


\subsection{5. Índice de Circularidade}

Simultaneamente ao coeficiente de compacidade, o índice de circularidade tende para a unidade à medida que a bacia se aproxima da forma circular e diminui à medida que a forma torna alongada. Para isso, utilizouse a seguinte equação:

$$
I C=\frac{12,57 * A}{p^{2}}
$$

em que IC é o índice de circularidade, Aa área de drenagem $\left(\mathrm{m}^{2}\right)$ e $\mathrm{P}$ o perímetro $(\mathrm{m})$.

\subsubsection{Declividade e Altitude}

O modelo digital de elevação hidrologicamente consistente (MDEHC) foi utilizado como entrada para a geração do mapa de declividade e da altitude. A imagem de declividade gerada foi do tipo contínua, por apresentar valores reais. As classes de declividade foram separadas em seis intervalos distintos, sugeridos pela Embrapa (1979), conforme mostrado no Quadro 1.

\subsubsection{Ordem}

A ordem dos cursos d'água pode ser determinada seguindo os critérios introduzidos por Horton (1945) e Strahler (1957). Utilizou-se neste trabalho a classificação apresentada por Strahler, em que os canais sem tributários são designados de primeira ordem. Os canais de segunda ordem são os que se originam da confluência de dois canais de primeira ordem, podendo ter afluentes também de primeira ordem. Os canais de terceira ordem originamse da confluência de dois canais de segunda ordem, podendo receber afluentes de segunda e primeira ordens, e assim sucessivamente (SILVEIRA, 2001). A junção de um canal de dada ordem a um canal de ordem superior não altera a ordem deste.

Quadro 1 - Classificação da declividade segundo a Embrapa (1979)

Table 1 - Slope classification according to Embrapa (1979)

\begin{tabular}{lc}
\hline Declividade & Discriminação \\
\hline $0-3$ & Relevo plano \\
$3-8$ & Relevo suavemente ondulado \\
$8-20$ & Relevo ondulado \\
$20-45$ & Relevo fortemente ondulado \\
$45-75$ & Relevo montanhoso \\
$>75$ & Relevo fortemente montanhoso \\
\hline
\end{tabular}

R. Árvore, Viçosa-MG, v.30, n.2, p.241-248, 2006

\subsubsection{Densidade de drenagem}

O sistema de drenagem é formado pelo rio principal e seus tributários. Seu estudo indica a maior ou menor velocidade com que a água deixa a bacia hidrográfica, sendo, assim, o índice que indica o grau de desenvolvimento do sistema de drenagem, ou seja, fornece uma indicação da eficiência da drenagem da bacia, sendo expressa pela relação entre o somatório dos comprimentos de todos os canais da rede - sejam eles perenes, intermitentes ou temporários - e a área total da bacia.

$\mathrm{O}$ índice foi determinado utilizando a equação:

$$
\mathrm{Dd}=\frac{\mathrm{L}_{\mathrm{t}}}{\mathrm{A}}
$$

sendo Dd a densidade de drenagem $\left(\mathrm{km} / \mathrm{km}^{2}\right), \mathrm{L}_{\mathrm{t}}$ comprimento total de todos os canais $(\mathrm{km})$ e A a área de drenagem $\left(\mathrm{km}^{2}\right)$.

\section{RESULTADOS E DISCUSSÃO}

No Quadro 2, mostram-se os resultados da caracterização da bacia hidrográfica do rio Debossan. A área de drenagem encontrada na bacia foi de 9,9156 $\mathrm{km}^{2}$ e seu perímetro, de $17,684 \mathrm{~km}$.

De acordo com os resultados, pode-se afirmar que a bacia hidrográfica do rio Debossan mostra-se pouco suscetível a enchentes em condições normais de precipitação, ou seja, excluindo-se eventos de intensidades anormais, pelo fato de o coeficiente de compacidade apresentar o valor afastado da unidade $(1,5842)$ e, quanto ao seu fator de forma, exibir um valor baixo $(0,3285)$. Assim, há uma indicação de que a bacia não possui forma circular, possuindo, portanto, uma tendência de forma alongada. Tal fato pode ainda ser comprovado pelo índice de circularidade, possuindo um valor de 0,3985. Em bacias com forma circular, há maiores possibilidades de chuvas intensas ocorrerem simultaneamente em toda a sua extensão, concentrando grande volume de água no tributário principal.

Em estudo realizado em Teixeira de Freitas, BA, constatou-se que em uma bacia com área igual a $0,589 \mathrm{~km}^{2}, 67,3 \%$ ocupada por floresta, e outra com área de $0,257 \mathrm{~km}^{2}$, com ocupação de $100 \%$ de pastagem, foram encontrados índices de circularidade de 2,96 e 2,01, respectivamente. Observou-se que picos de vazão com aumento da precipitação proporcionaram a saída rápida da água dessas bacias logo após a precipitação (AZEVEDO, 1995). 
Quadro 2 - Características físicas da bacia hidrográfica do rio Debossan, Nova Friburgo, RJ, 2004

Table 2-Physical characteristics of the Debossan river watershed, Nova Friburgo, RJ, 2004

\begin{tabular}{lc}
\hline Características Físicas & Resultados \\
\hline Área de drenagem $\left(\mathrm{Km}^{2}\right)$ & 9,9156 \\
Perímetro $(\mathrm{Km})$ & 17,684 \\
Coeficiente de compacidade (Kc) & 1,5842 \\
Fator de forma (F) & 0,3285 \\
Índice de circularidade (IC) & 0,3985 \\
Declividade máxima (\%) & 150,89 \\
Declividade média (\%) & 32,61 \\
Declividade mínima (\%) & 0,13 \\
Altitude máxima (m) & $1.635,0$ \\
Altitude média (m) & $1.310,6$ \\
Altitude mínima (m) & $1.026,2$ \\
Ordem da bacia & 3 \\
Densidade de drenagem $\left(\mathrm{km} / \mathrm{km}^{2}\right)$ & 2,3579 \\
\hline
\end{tabular}

A densidade de drenagem encontrada na bacia hidrográfica do rio Debossan foi de $2,35 \mathrm{~km} / \mathrm{km}^{2}$. De acordo com Villela e Mattos (1975), esse índice pode variar de $0,5 \mathrm{~km} / \mathrm{km}^{2} \mathrm{em}$ bacias com drenagem pobre a $3,5 \mathrm{~km} / \mathrm{km}^{2}$, ou mais, em bacias bem drenadas, indicando, assim, que a bacia em estudo possui média capacidade de drenagem. O índice de densidade de drenagem encontrado na bacia hidrográfica do rio Turvo Sujo, em MG, foi de $4,6 \mathrm{~km} / \mathrm{km}^{2}$, mostrando que aquela bacia apresenta elevada capacidade de drenagem (SANTOS, 2001). A bacia hidrográfica do rio Juatuba, MG, obteve valores de densidade de drenagem para bacias de áreas equivalentes a $5,2 \mathrm{~km}^{2}, 80,2 \mathrm{~km}^{2}$ e $265,0 \mathrm{~km}^{2}$, iguais a 1,$63 ; 1,50 ;$ e 1,91 , respectivamente. Assim, de acordo com esse autor, essas bacias poderiam ser enquadradas como medianamente drenadas (EUCLYDES, 1992).

A densidade de drenagem é um fator importante na indicação do grau de desenvolvimento do sistema de drenagem de uma bacia. Esses valores ajudam substancialmente o planejamento do manejo da bacia hidrográfica. O sistema de drenagem da bacia em estudo, de acordo com a hierarquia de Strahler, possui ramificação de terceira ordem, o que significa pouca ramificação para a escala do mapa utilizado.

De acordo com a Figura 2, a bacia hidrográfica do rio Debossan é de terceira ordem, na hierarquia de Strahler e escala de 1:50.000. Isso indica que o sistema de drenagem da bacia é pouco ramificado, já que possui grande área.

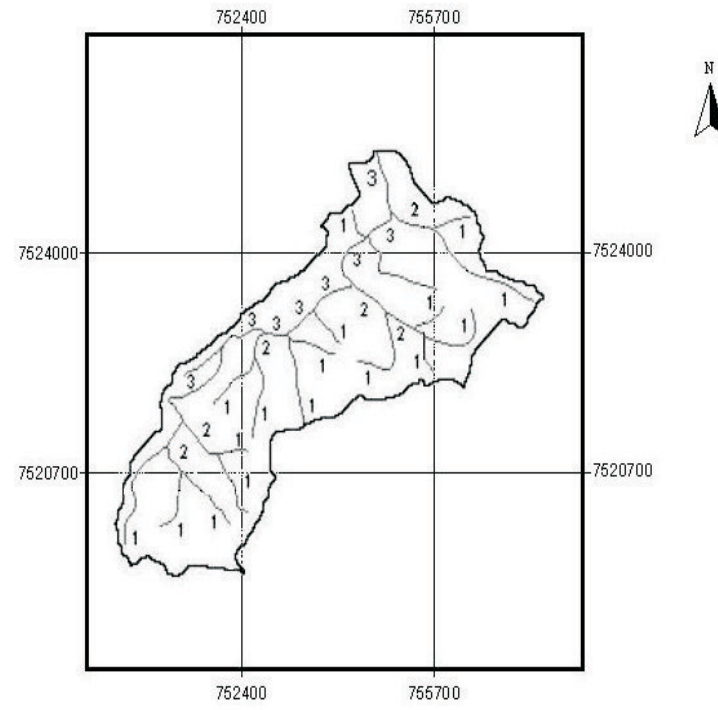

Figura 2 - Ordenamento da bacia hidrográfica do rio Debossan, Nova Friburgo, RJ, conforme metodologia de Strahler (1957).

Figure 2-Watershed order of the Debossan river, Nova Friburgo, RJ, according to methodology by Strahler (1964).

No Quadro 3, apresentam-se as informações quantitativas associadas à declividade do terreno da bacia. Observa-se, nesse quadro, que a maior parte do relevo corresponde a forte ondulado, com $47,61 \%$. A declividade influencia a relação entre a precipitação e o deflúvio da bacia hidrográfica, sobretudo devido ao aumento da velocidade de escoamento superficial, reduzindo a possibilidade da infiltração de água no solo. Na bacia em estudo, essa alta declividade parece ser compensada pela boa cobertura vegetal.

Quadro 3 - Distribuição das classes de declividade da bacia hidrográfica do rio Debossan, Nova Friburgo, RJ, 2004

Table 3 -Distribution of watershed slope classes of the Debossan river, Nova Friburgo, RJ, 2004

\begin{tabular}{lccr}
\hline Declividade $(\%)$ & Relevo & Área $\left(\mathrm{km}^{2}\right)$ & $\%$ \\
\hline $0-3$ & Plano & 0,1072 & 1,08 \\
$3-8$ & Suave ondulado & 0,5324 & 5,37 \\
$8-20$ & Ondulado & 2,1924 & 22,11 \\
$20-45$ & Forte ondulado & 4,7211 & 47,61 \\
$45-75$ & Montanhoso & 2,1583 & 21,76 \\
$>75$ & Forte montanhoso & 0,2042 & 2,05 \\
\hline
\end{tabular}

R. Árvore, Viçosa-MG, v.30, n.2, p.241-248, 2006 
A cobertura vegetal exerce função hidrológica de interceptação e redistribuição da água da chuva. A maior quantidade da água da chuva atravessa o dossel da floresta, atingindo o piso florestal recoberto de serapilheira. Nesse processo, o papel exercido pela serapilheira na diminuição da erosão superficial é fundamental, evitando o selamento do solo e permitindo a infiltração da água no solo (COELHO NETO, 1985). Os macroporos biogênicos, inclusive os dutos de raízes mortas, exercem, juntamente com os sistemas radiculares, visto por Basile et al. (2003), uma função hidrológica importante, propiciando alto valor de permeabilidade às camadas superficiais dos solos florestais.

A remoção da vegetação em um ambiente florestal leva, consequientemente, a processos erosivos, gerando degradação do ambiente, podendo se propagar para áreas adjacentes. Assim, a declividade e a cobertura vegetal tornam-se fatores importantes na tomada de decisão de um manejo adequado da bacia hidrográfica, visto que influenciam a precipitação efetiva, escoamento superficial e fluxo de água no solo, dentre outros.

A Figura 3 ilustra a distribuição das altitudes na bacia, constatando-se uma altitude média de $1.310 \mathrm{~m}$. No Quadro 4, verifica-se a porcentagem da área de drenagem nas faixas altimétricas definidas. Observase, nesse quadro, que a maior parte da altitude, de acordo com a área da bacia, apresenta-se na faixa entre 1.300 e $1.400 \mathrm{~m}$, correspondendo a $26,77 \%$.

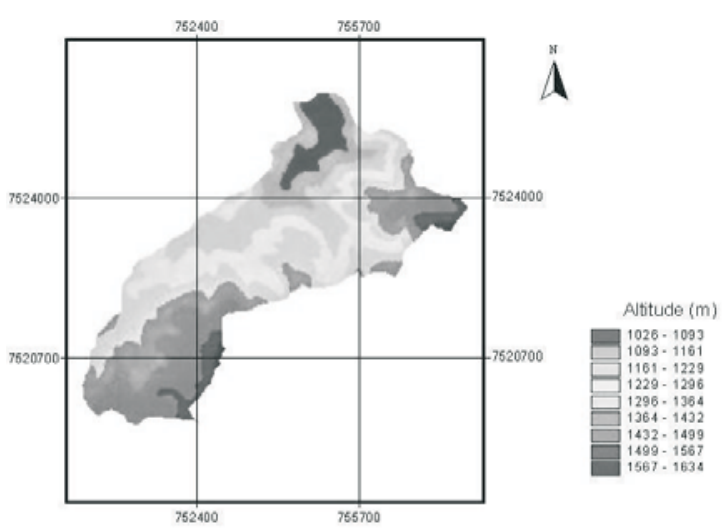

Figura 3 - Distribuição da altitude de acordo com a área da bacia hidrográfica do rio Debossan, Nova Friburgo, RJ, 2004.

Figure 3 -Distribution of altitude according to the watershed area of the Debossan river, Nova Friburgo, RJ, 2004.

R. Árvore, Viçosa-MG, v.30, n.2, p.241-248, 2006
Quadro 4 - Distribuição da altitude de acordo com a área da bacia hidrográfica do rio Debossan, Nova Friburgo, RJ, 2004

Table 4 -Distribution of altitude according to the watershed area of the Debossan river, Nova Friburgo, RJ, 2004

\begin{tabular}{ccc}
\hline Altitude & Área $\left(\mathrm{km}^{2}\right)$ & $\%$ \\
\hline $1026-1100$ & 0,5934 & 5,98 \\
$1100-1200$ & 1,3690 & 13,80 \\
$1200-1300$ & 2,5994 & 26,21 \\
$1300-1400$ & 2,6550 & 26,77 \\
$1400-1500$ & 2,2320 & 22,50 \\
$1500-1600$ & 0,4550 & 4,58 \\
$1600-1635$ & 0,011 & 0,12 \\
\hline
\end{tabular}

De acordo com Castro Jr. (2001), em altitudes elevadas, a temperatura é baixa, e apenas pequena quantidade de energia é utilizada para evaporar a água, ao passo que, em altitudes baixas, quase toda a energia absorvida é usada para evaporação da água. As altitudes elevadas tendem a receber maior quantidade de precipitação, além de a perda de água ser menor. Nessas regiões, a precipitação normalmente excede a evapotranspiração, ocasionando um suprimento de água que mantém o abastecimento regular dos aqüíferos responsáveis pelas nascentes dos cursos d'água.

\section{CONCLUSÃO}

De acordo com os resultados, pode-se concluir que:

- A caracterização morfométrica da bacia hidrográfica do rio Debossan aponta para uma bacia de forma mais alongada, sendo comprovado pelo índice de circularidade, coeficiente de compacidade e fator de forma. Isso denota um forte controle estrutural da drenagem.

- A densidade de drenagem é de 2,35 km/ $\mathrm{km}^{2}$, podendo-se afirmar que a bacia em estudo apresenta uma profunda dissecação fluvial e perenidade, em função da pluviosidade elevada.

- A bacia hidrográfica do rio Debossan é de terceira ordem, apontando que o sistema de drenagem da bacia é pouco ramificado.

- As características da declividade da bacia indicam que $47,61 \%$ da área possui relevo forte ondulado e altitude média de $1.310 \mathrm{~m}$. 


\section{AGRADECIMENTOS}

À Concessionária de Águas e Esgotos de Nova Friburgo - CAENF, em especial ao biólogo Ernani de Almeida e à Rita Alves, pela atenção dispensada e pelo apoio imediato ao projeto; e ao $\mathrm{CNPq}$, pela concessão de bolsa durante parte do período de estudos.

\section{REFERÊNCIAS BIBLIOGRÁFICAS}

\author{
AZEVEDO, E.C. Vazão e características \\ físicas e químicas do deflúvio de \\ microbacias hidrográficas cobertas \\ com mata nativa, pastagem e Eucalyptus \\ grandis. 1995. 92 f. Dissertação (Mestrado em \\ Solos e Nutrição de Plantas) - Universidade \\ Federal de Viçosa, Viçosa, 1995.
}

BASILE, R.O.N.C.; NEGREIROS, A.B.; MIGUEL, F.L.C.G. A estrutura da Floresta Atlântica de encosta e arquitetura de raízes arbóreas: maciço da Tijuca RJ. In: SIMPÓSIO BRASILEIRO DE GEOGRAFIA FÍSICAAPLICADA, 10., 2003, Rio de Janeiro. Anais... Rio de Janeiro: 2003. v.1, p.1909-1917.

BERNARDES, L.N.C. Tipos de clima do estado do Rio de Janeiro. Revista Brasileira de Geografia, v. 14, n. 1, p. $57-80.1952$.

CASTRO JR., E. O papel da fauna endopedônica na estruturação física dos solos e o seu significado para a hidrologia de superfície. 2001. 150 f. Dissertação (Mestrado em Geografia) Universidade Federal do Rio de Janeiro, Rio de Janeiro, 2001.

COELHO NETO, A.L. O geoecossistema da Floresta da Tijuca. In: ABREU, M.A.A.

Natureza e sociedade no Rio de Janeiro. Rio de Janeiro: Biblioteca Carioca/ IPLANRIO, 1985. p.104-142.

\section{EMPRESA BRASILEIRA DE PESQUISA}

AGROPECUÁRIA - EMBRAPA. Serviço Nacional de Levantamento e Conservação de Solos (Rio de Janeiro, RJ). Súmula da 10 . reunião Técnica de Levantamento de Solos. Rio de Janeiro, 1979. 83p. (EMBRAPA-SNLCS.

Micelânea, 1).
EUCLYDES, H.P. Regionalização de vazões máximas e mínimas para a bacia do rio Juatuba - MG. 1992. 66 f. Dissertação (Mestrado em Engenharia Agrícola) Universidade Federal de Viçosa, Viçosa, 1992.

FERREIRA, C. C. M. Zoneamento agroclimático para implantação de sistemas agroflorestais com eucaliptos, em Minas Gerais. Viçosa, MG: Universidade Federal de Viçosa, 1997. 158p.

GARBRECHT, J.; MARTZ, L.W. Digital elevation model issues in water resources modeling. ESRI, USERS CONFERENCE, 19., 1999, San Diego. Proceedings... San Diego: 1999. CD-ROM.

GUERRA, A.J.T.; CUNHA, S. B. Degradação ambiental. In: CUNHA, S. B. Geomorfologia e meio ambiente. Rio de Janeiro: Bertrand Brasil, 1996. p. 337-339.

HORTON, R. Erosional development of streams and their drainage basins: hidrophysical approach to quatitative morphology. New York: Geological Society of American Bulletin, 1945. v.56. p. 807-813.

RADAMBRASIL. Levantamento de recursos naturais. Rio de Janeiro: Projeto RADAMBRASIL, 1983. v. 32.775p.

RIZZINI, C.T. Tratado de fitogeografia do Brasil. São Paulo: Universidade de São Paulo, 1979. v. 2. 374p.

SANTOS, A.R. Caracterização morfológica, hidrológica e ambiental da bacia hidrográfica do rio Turvo Sujo, Viçosa, MG. 2001. 141f. Tese (Doutorado em Recursos Hídricos), Universidade Federal de Viçosa, Viçosa, 2001.

SILVEIRA, A.L.L. Ciclo hidrológico e bacia hidrográfica. In: TUCCI, C.E.M. (Org.). Hidrologia: ciência e aplicação. São Paulo: EDUSP, 2001. p 35-51.

SOUZA. C.G., et al. Caracterização e manejo integrado de bacias hidrográficas. Belo Horizonte: EMATER, 2002. 124p.

R. Árvore, Viçosa-MG, v.30, n.2, p.241-248, 2006 
STRAHLER, A.N. Quantitative analysis of watershed geomorphology. New Halen:

Transactions: American Geophysical Union, 1957. v.38. p. 913-920.

THORNTHWAITE, C.W.; MATHER, J.R. The water balance. New Jersey: Laboratory of Climatology, 1955. 104p.
VELLOSO, H.P.; RAGEL FILHO, A.L.R.; LIMA, J.C.A. Classificação da vegetação brasileira adaptada a um sistema universal. Rio de Janeiro: IBGE, 1991. 124p.

VILLELA, S.M.; MATTOS, A. Hidrologia aplicada. São Paulo: McGraw-Hill do Brasil, 1975. 245p. 